\title{
An approach for handling environmental and economic conflicts in the context of sustainable building
}

\author{
K. Allacker ${ }^{1}$, D. Trigaux ${ }^{1}$ \& F. De Troyer ${ }^{1}$ \\ ${ }^{I}$ Department of Architecture, Faculty of Engineering, \\ Katholieke Universiteit Leuven, Belgium
}

\begin{abstract}
When striving for sustainable buildings, the focus is often set on the optimization of the building environmental impact. In that perspective, the Life Cycle Assessment (LCA) method is widely used to calculate the environmental impact and through comparative studies, the preferred design options are chosen. As costs are however a very important issue in decision making, it is important to include costs in the analysis too. Although decisions are often only based on investment cost, we recommend considering also the life cycle cost (LCC) to guarantee long term affordability. This paper illustrates the importance of considering both aspects by discussing the optimisation of 16 representative residential buildings in Belgium from both an environmental and financial perspective. The question raises how to handle contradictions between the results of an LCA and LCC study of a building. The paper discusses and illustrates the promising approach of monetary valuation of environmental impacts. Recommendations are formulated based on the experience in the Belgian context.
\end{abstract}

Keywords: life cycle assessment, life cycle costing, monetary valuation, Pareto optimisation, weighting.

\section{Introduction}

There is a general consensus on the definition of sustainable development as defined by Gro Harlem Brundtland "development that meets the needs of the present without compromising the ability of future generations to meet their own needs" [1]. It is furthermore broadly recognised that sustainable development 
enhances three important pillars: the environmental, economic and social pillar. Despite this general consensus, there is less agreement on how to quantify each of these or assess these in a qualitative way. Neither is there a widely supported approach on how to combine the three pillars into an overall assessment.

To date, we see a proliferation of sustainability assessment methods and certification labels for buildings. Each of these uses its own specific approach for assessing one or more of the three sustainability pillars. Within this large set of available methods/certification systems we can distinguish (category 1) methods that focus in detail on one of the three pillars (most of the time in a quantitative way) and (category 2) methods that address the three pillars in an overall but more subjective way (most of the time semi-quantitatively, i.e. based on a multicriteria analysis).

Within the first category of quantitative methods focusing mainly on a single sustainability pillar, most often a life cycle approach is followed. The assessment of the environmental impacts is most advanced. A life cycle assessment (LCA) is often used. The wide recognition of this method by the scientific committee is clear from the international standards ISO 14040 [2] and ISO 14044 [3]. In the specific context of sustainable construction, this is reflected in the European Standard EN15804 [4]. Many LCA studies of construction products moreover prove the applicability and viability of the method, amongst others by Aktas and Bilec [5], Blengini and Di Carlo [6], Jönssen et al. [7], Li et al. [8] and Stazi et al. [9]. Also for the assessment of the economic issues a life cycle approach is possible by using the well-established life cycle costing (LCC) approach. As defined by the building and construction assets standard ISO 15686, it enables the calculation of "the total cost of a building or its parts throughout its life, including the costs of planning, design, acquisition, operations, maintenance and disposal, less any residual value" [10]. The LCC method is also used in the European Standard prEN 16627 (current status: under approval) concerning the economic performance of buildings. The assessment of the social aspects is less advanced, but attempts are being made for a social life cycle assessment (SLCA). This is for example reflected in the handbook 'Guidelines for Social Life Cycle Assessment of Products' of UNEP/SETAC [11].

Within the environmental and social pillar there are typically several indicators assessed, expressed in different units. In consequence equilibrium needs to be found between comprehensiveness and simplification (for communication and decision taking reasons). Attempts are therefore made to combine the different indicators into a single score (index). Several approaches are followed. Two important ones in the terms of their wide application are normalisation combined with weighting on the one hand and monetary valuation on the other hand. Through normalisation the different indicators are compared to the impact of a common reference and hence are expressed in a dimensionless unit. Weighting means each of the indicators is assigned an importance and a single score is calculated based on the sum of the weighted normalised values. The single score is typically expressed in Ecopoints. Monetary valuation is an approach that expresses all indicators in a monetary unit (e.g. EURO). The environmental impacts are then expressed in external environmental 
costs. Several methods exist for the calculation of these external environmental costs. An extensive overview of possible approaches is given by Huppes et al. [12]. The advantage of monetary valuation compared to normalisation/weighting is that these are expressed in the same unit as financial costs and hence environmental impacts and economic issues can be assessed simultaneously: these can be added up and decisions can be taken based on total costs (i.e. sum of environmental and financial costs). The approach of monetary valuation could furthermore be extended for the social pillar, by expressing social impacts in social external costs. This would hence allow taking straightforward decisions in case of contradictions based on the three sustainability pillars.

The second category of methods comprises of certification systems such as LEED [13], BREEAM [14] and the German DGNB [15]. These methods cover a broad range of indicators which are then translated in a single score via a (subjective) multi-criteria analysis.

Because the approach of monetary valuation seems promising in terms of a consistent approach for the three sustainability pillars, this method was explored for the assessment of buildings in the Belgian context. In the first phase, the method was limited to the environmental and economic issues through a combination of LCA and LCC. The approach used is further discussed and illustrated in this paper.

\section{Objectives}

One of the objectives of the research presented here was to search for the most preferred technical solutions for 16 representative dwellings in the Belgian context from both an environmental and financial perspective. It was investigated if decisions based on both criteria, were identical. If not, how decisions can be taken considering both criteria. A method is proposed combining both environmental and financial optimisation criteria, based on the Pareto principle. The methodological steps and insights are described in section 3 of this paper. Section 4 summarises the results of the implementation of the methodology to the 16 representative dwellings and the final, fifth section, summarises the main conclusions and formulates recommendations for an integrative assessment and further research.

\section{Methodology}

\subsection{Environmental impact assessment}

For the assessment of the life cycle environmental impacts of the 16 residential buildings, the LCA method was used. For a further explanation of the LCA methodology, we refer to the international standards and previously mentioned papers reporting LCA studies of building products and buildings. We will limit this section to a summary of the most important methodological decisions in our 
study in order to allow for a correct interpretation of the results. The Swiss Ecoinvent database was used for the inventory of the environmental data. The data were moreover adapted to improve their representativeness for the Belgian context (i.e. by adapting the Swiss electricity mix and transport means to the European ones, done by VITO (Flemish Institute for Technological Research)). Several scenarios are needed when conducting an LCA study of a building. The main assumptions can be summarised as follows: building life span equals 60 years (with a sensitivity analysis of 30 and 120 years), the impacts during the construction phase were limited to material loss with an assumption of $5 \%$ on average for the different materials, the cleaning, maintenance and replacement activities differ for the different technical solutions and were determined based on a literature study (i.e. activities, frequencies) and the transport and end-of-life scenarios were determined based on surveys (by the Belgian Building Research Institute (BBRI)). More detailed data on each of the assumptions can be found in Allacker [16]. For the impact assessment we refer to the subsequent section.

\subsection{Monetary valuation}

The environmental external costs were mainly based on the willingness to pay approach and were retrieved by combining different existing methods. A detailed discussion on external costs, monetary values and an extended justification of the selected methods was elaborated in Allacker and De Nocker [17]. In summary, the environmental external cost referred to in this paper covers the impacts due to the emission of $\mathrm{CO}_{2}$-equivalents, $\mathrm{SO}_{2}, \mathrm{NO}_{\mathrm{x}}, \mathrm{PM} 2.5, \mathrm{NH}_{3}, \mathrm{VOC}$; human health effects due to carcinogens, respiratory effects, radiation and ozone layer depletion; impact on ecosystem quality (acidification, eutrophication, ecotoxicity and land use); and finally depletion of resources (minerals and fossil fuels).

\subsection{Life cycle costing (LCC)}

Life cycle costing (LCC) is a well-known and broadly accepted method to assess the life cycle costs of products in general, and buildings in specific. An LCC study takes into account the costs of a building over its entire life span. These costs obviously occur at different moments in time and hence their present value is calculated in order to determine the total life cycle cost of a building (i.e. sum of the present values of all costs). As it is unknown how costs will evolve in time, assumptions are needed regarding several economic parameters. For a further explanation on all sources used and assumptions made we refer to a previous paper by Allacker [18] and Allacker and De Troyer [19].

\subsection{Pareto optimisation (2 dimensions)}

As the aim of the study was to search for the most optimal technical and constructive composition, several alternatives were defined for each building and a comparative analysis was made. The alternatives for each dwelling ranged in insulation level, air-tightness, construction technique (i.e. solid versus 
skeleton) choice of building materials and choice of technical services. For each of the dwellings, about 23,000 variants were analysed.

For each of these variants, the external environmental cost and financial cost were determined for both the construction phase (initial cost) and life cycle (life cycle cost) of the building. In a subsequent step a Pareto optimisation was made based on minimum life cycle cost and minimum investment cost. This allowed searching for these options which led to the highest reduction in life cycle cost for the lowest increase in investment cost. For each of the dwellings a set of Pareto optima were defined for the environmental impact, financial cost and total cost (i.e. sum of the environmental and financial cost). This is illustrated in figure 1 for the environmental cost for one of the detached dwellings. The Pareto optima were determined for the two construction techniques separately. The absolute optimum on both Pareto fronts was defined as the option with the lowest life cycle cost (assuming there was no budget restriction). As it was however noticed that the "end" of the Pareto front very often had a weak slope (i.e. nearly horizontal), also a sub-optimum was defined. This is the option on the Pareto front at the end of the steep slope (i.e. still a high reduction in life cycle cost for a relatively small increase in investment cost). This is elaborated in more detail in a previous publication by Allacker [18]. In the remaining of this paper only the sub-optima of the dwellings will be discussed. For the most important options in the cloud of solutions, the most relevant data are mentioned as well (i.e. initial financial cost, life cycle financial cost, K-value (reflecting insulation level and compactness) and E-value (energy performance).

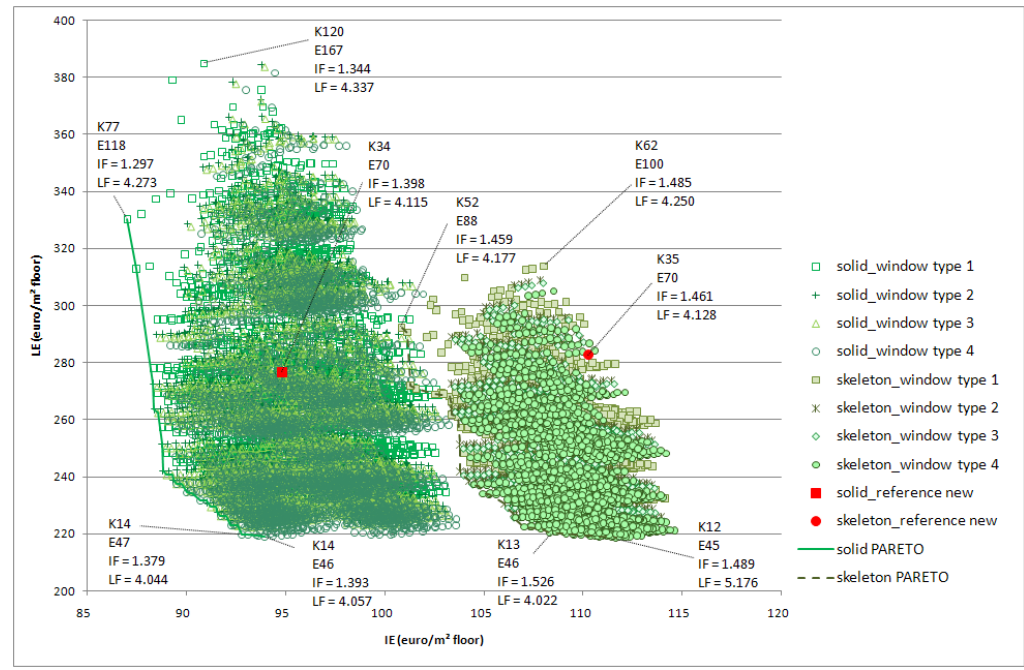

Figure 1: $\quad$ Detached dwelling type 1: Initial environmental (IE) and life cycle environmental cost (LE) of the analysed variants, indicating the Pareto optima [16]. 


\subsection{6 case studies}

A selection of 16 representative residential buildings was made based on a national statistical socio-economic survey conducted in 2001 [20]. The selected dwellings cover four types: detached houses, semi-detached houses, terraced houses and apartments. For each of these, representative dwellings were selected for four construction periods: before 1945, 1945-1970, 1971-1990 and 1991-2001. For each of the 16 buildings, a wide range of new-built dwellings were investigated (see previous section) and the Pareto optima were determined based on environmental, financial and total cost.

\section{Results of case studies}

The tables 1 to 4 represent the sub-optima from an environmental (EC), financial (FC) and total (TC) cost perspective for the 16 buildings. For the three sub-optima of each dwelling the technical solution for the different building elements (i.e. floor on grade, outer wall, flat roof, pitched roof, window) are shown in the columns 3 to 7. These are indicated by their symbol (i.e. GRFL, OW, FR, PR and WIN respectively) and a number. The different numbers indicate different technical solutions. The aim here is only to show different choices, the exact representation of each of the numbers is not elaborated here, but can be found in Allacker [16]. Columns 8 and 9 represent the K-value and E-value respectively. The lower the $\mathrm{K}$ and $\mathrm{E}$ values, the lower the thermal losses and the lower the net energy demand. Columns 10 to 15 represent the initial (IE, IF, IT) and life cycle cost (LE, LF, LT) from an environmental, financial and total perspective.

The results illustrate that for all dwellings, the sub-optima from an environmental perspective differ from the financial sub-optima. We furthermore see that for 8 of the 16 dwellings, the sub-optima based on total cost differ from the financial sub-optima. For these dwellings, the internalisation of the environmental external cost hence has an influence on decision taking.

A detailed analysis of the Pareto optima moreover revealed that environmental and financial priorities differ. Measures which lead to a reduction in life cycle external cost do not always imply a reduction in life cycle financial cost. Despite this difference in priorities, the analysis also showed that for most dwellings, the environmental sub-optima led for 10 of the 16 dwellings to a reduction in life cycle financial cost. Moreover, only a small increase $(6 \%$ on average) in financial investment cost was noticed.

\section{Conclusions and recommendations}

In the analysis, within the hypotheses mentioned above, of the 16 representative residential buildings in Belgium discrepancies are noticed between the importance of the different life cycle phases and processes in terms of environmental and financial costs. While a reduction in the heating demand is the highest priority from an environmental point of view, reducing the cleaning and maintenance cost should be primarily reduced from a financial perspective. 


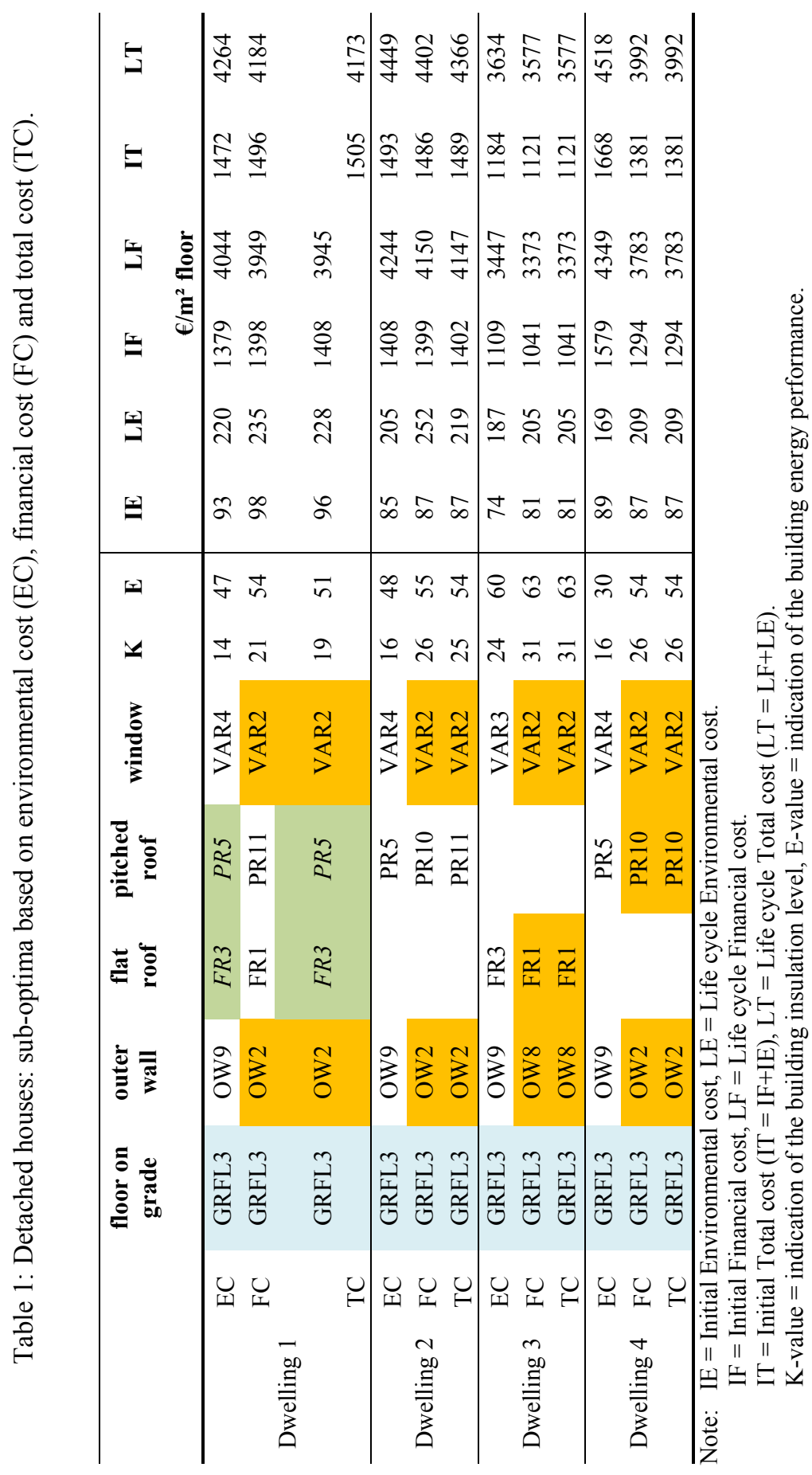




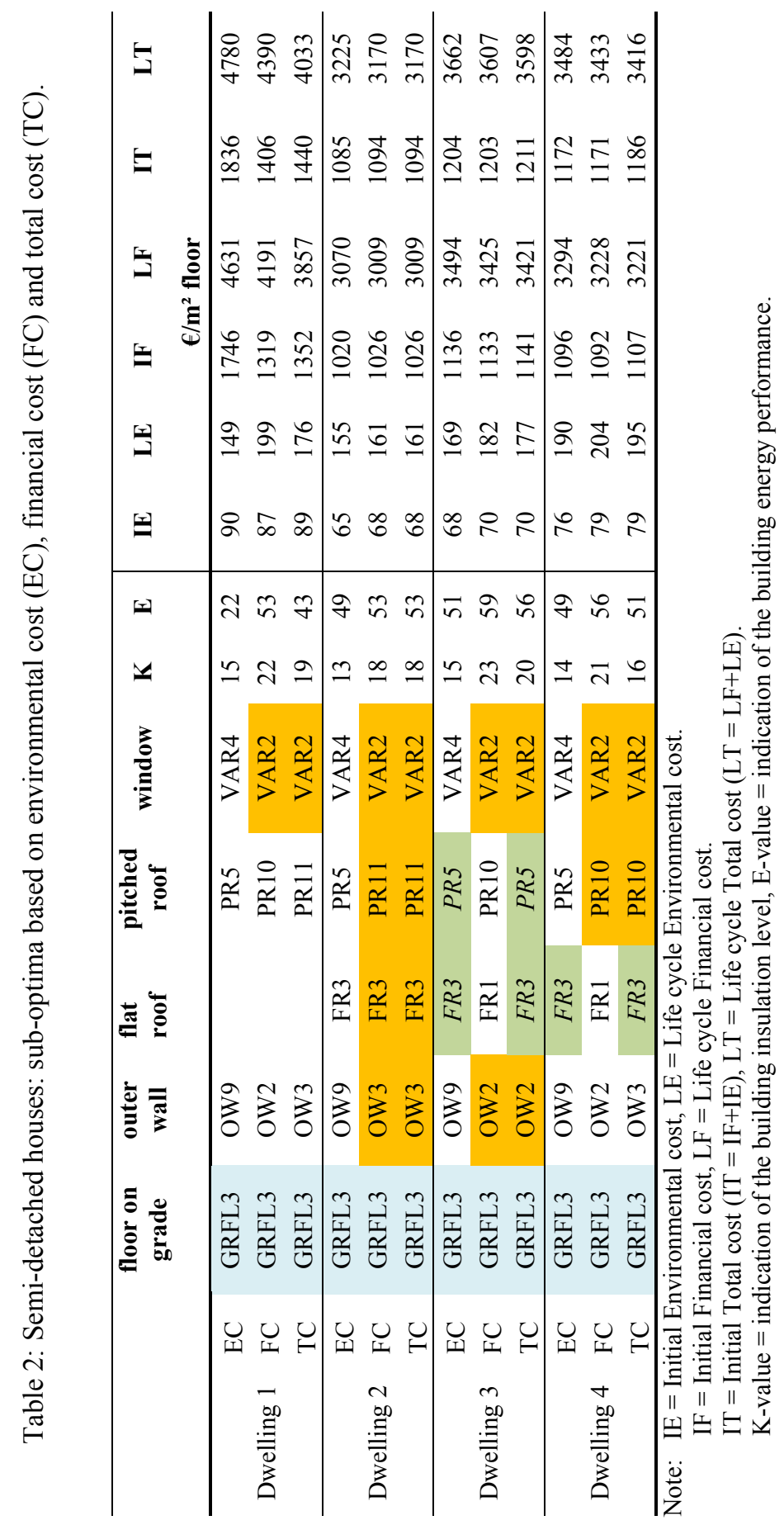




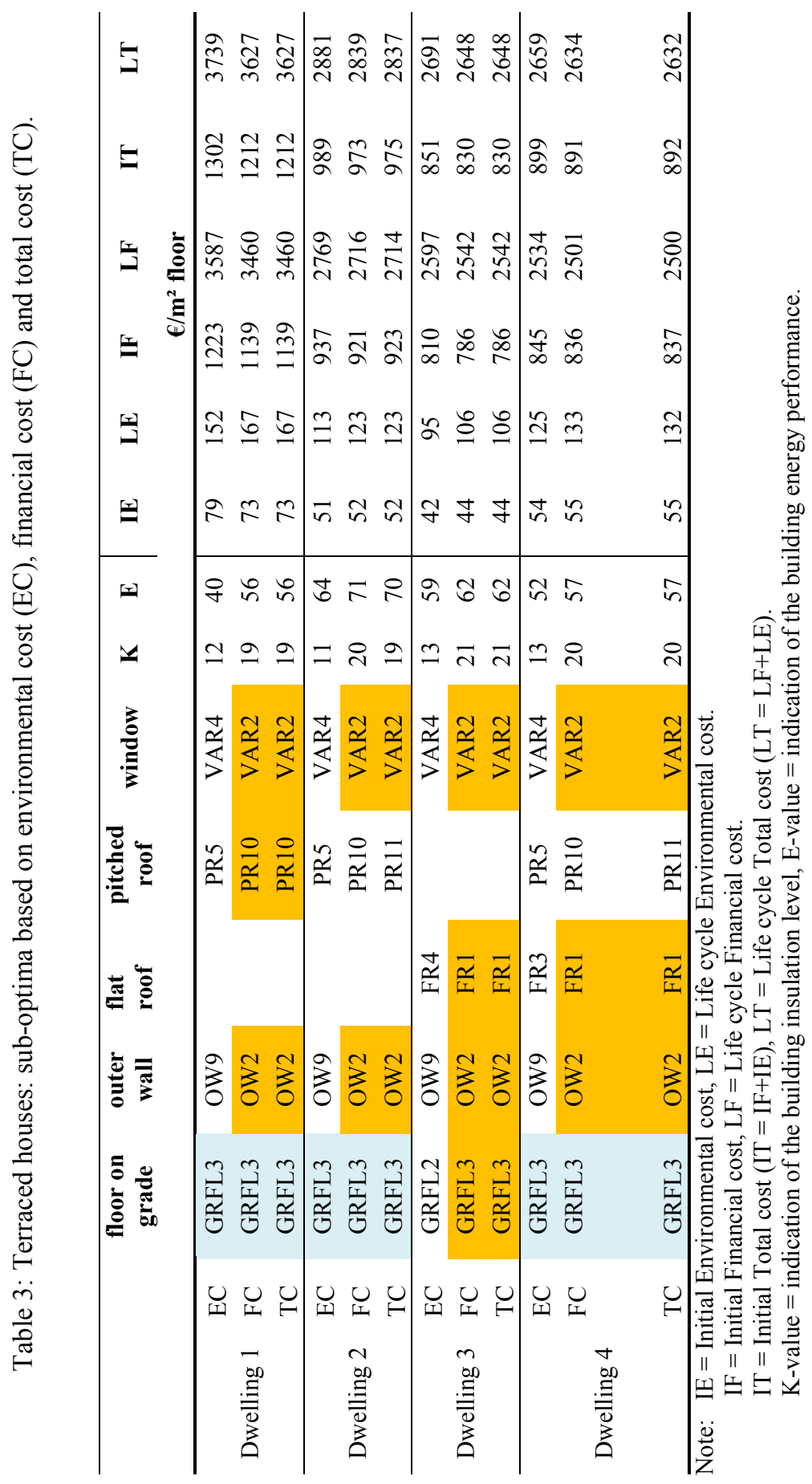




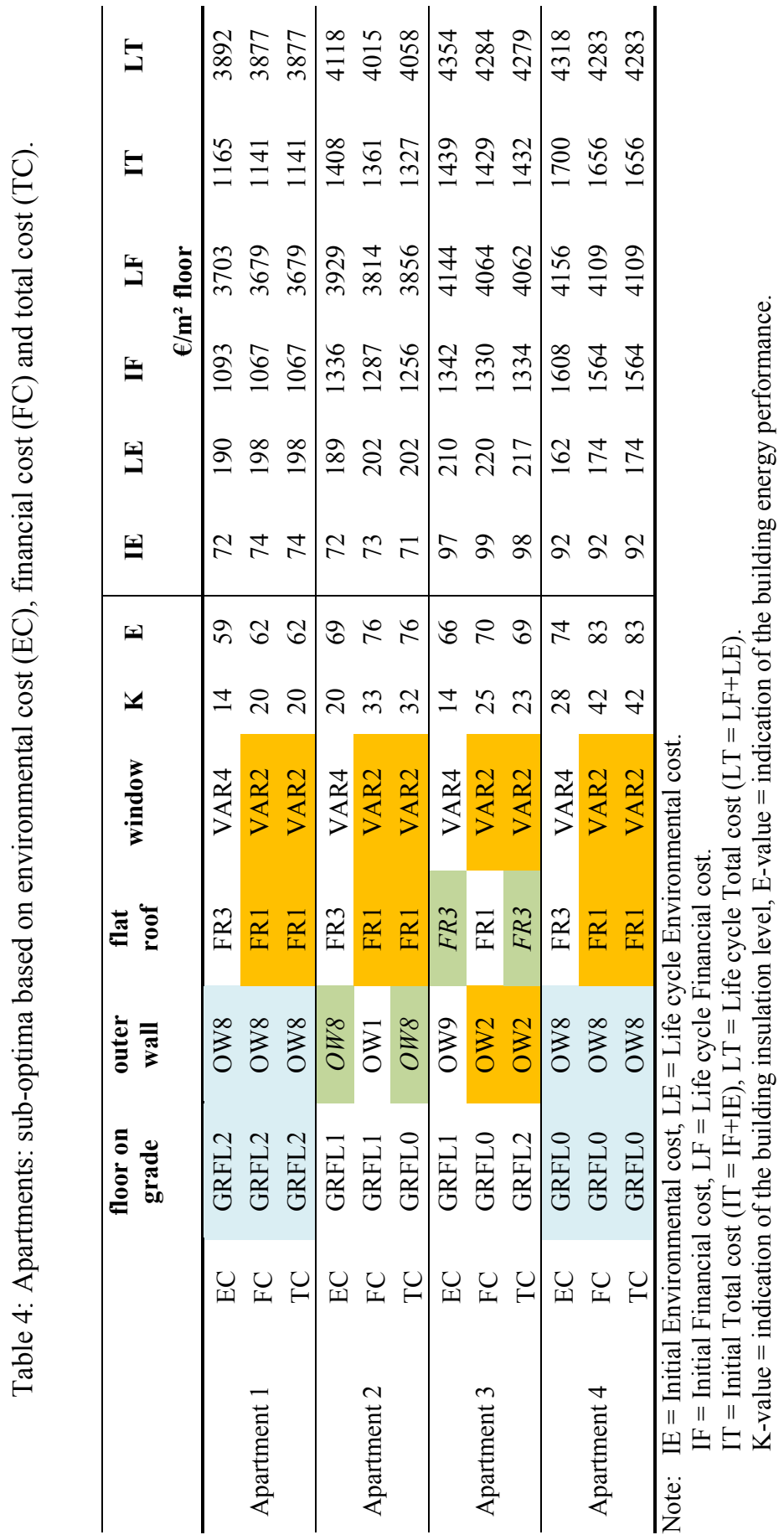


This difference in priorities confirms the need for an overall assessment of both environmental impacts and financial costs.

The analysis furthermore clarified that the optimum insulation level and optimum energy performance level differ from an environmental and financial point of view. From an environmental perspective we should strive for higher insulation levels and a better energy performance of our buildings than from a financial perspective. The net energy demand of the optima from a financial perspective equals on average $41 \mathrm{kWh} / \mathrm{m}^{2}$ floor, year. From an environmental perspective it equals $28 \mathrm{kWh} / \mathrm{m}^{2}$ floor, year.

Sensitivity analysis of the life span confirmed the importance of this parameter as different results were obtained for a building life span of 30 years compared to a building life span of 60 years. Lower optimal insulation levels were identified when considering a shorter building life span. The results were however approximately identical for a life span of 60 and 120 years.

The analysis finally revealed that the environmental cost represents only 5 to $10 \%$ of the total life cycle cost. The highest contribution of the environmental cost was noted for heating (approximately 30\% of the total cost). Based on this result we can conclude that adding the environmental external cost to the financial cost would not lead to unaffordable housing, except for dwellings with a high energy demand.

We would like to conclude that environmental external costs is promising because (a) it is an easy communication tool (i.e. EURO is easy to understand) and (b) it allows to make overall decisions based on environmental and financial costs. However, we would also like to stress the importance of considering environmental and financial costs separately as environmental costs (calculated with our approach) proved to be relatively low compared to financial costs. They hence only play a minor role in decisions based on total costs. Considering both separately allows checking the priorities from both an environmental and financial perspective and hence allows gaining insights in both issues.

\section{Acknowledgements}

The above analysis was part of a $\mathrm{PhD}$ research within the SuFiQuaD-project "Sustainability, Financial and Quality evaluation of Dwelling types". Special thanks go to the Belgian Science Policy - Science for a Sustainable Development for financing the project. The collaboration of the colleagues of VITO and BBRI is also acknowledged.

\section{References}

[1] WCED, Our Common Future, US: Oxford University Press, 1987.

[2] ISO, ISO 14040 - Environmental management - Life cycle assessment Principles and framework, International Organisation for Standardisation, 2006a.

[3] ISO, ISO 14044 - Environmental management - Life cycle assessment Requirements and guidelines, International Organisation for Standardisation, 2006b. 
[4] European Committee for Standardisation, EN: 15804 - Sustainability of construction works - Environmental product declarations Communication format business-to-business, European Committee for Standardisation, 2012.

[5] Aktas, C.B. \& Bilec, M.M., Impact of lifetime on US residential building LCA results. The International Journal of Life Cycle Assessment, 17, pp. 337-349, 2012.

[6] Blengini, G.A. \& Di Carlo, T., Energy-saving policies and low-energy residential buildings: an LCA case study to support decision makers in Piedmont (Italy). The International Journal of Life Cycle Assessment, 15, pp. 652-665, 2010.

[7] Jönssen, A., Björklund, T. \& Tillman, A.M., LCA of Concrete and Steel Building Frames. The International Journal of Life Cycle Assessment, 3(4), pp. 216-224, 1998.

[8] Li, X., Zhu, Y. \& Zhang, Z., An LCA-based environmental impact assessment model for construction processes. Building and Environment, 45, pp. 766-775, 2010.

[9] Stazi, F., Mastrucci, A. \& Munafò, P., Life cycle assessment approach for the optimization of sustainable building envelopes: An application on solar wall systems. Building and Environment, 58, pp. 278-288, 2012.

[10] ISO, ISO 15686-1 - Buildings and constructed assets - Life cycle assessment - Requirements and guidelines. International Organisation for Standardisation, 2006c.

[11] UNEP/SETAC., Guidelines for Social Life Cycle Assessment of Products. United Nations Environment Programme, 2009.

[12] Huppes, G., Davidson, M. D., Kuyper, J., van Oers, L., Udo de Haes, H.A. \& Warringa, G., Eco-efficient environmental policy in oil and gas production in The Netherlands. Ecological Economics, 61, pp. 43-51, 2007.

[13] USGBC. LEED for Homes - Rating System version 2008. USGBC, 2007.

[14] BRE. BREEAM. www.breeam.org/

[15] DGNB GmBH. The DGNB system. www.dgnb-system.de/

[16] Allacker, K., Sustainable Building: The development of an evaluation method, PhD dissertation, KU Leuven, 2010.

[17] Allacker, K. \& De Nocker, L., Approach for calculating the environmental external costs of the Belgian building sector. Journal of Industrial Ecology, 16(5), pp. 710-721, 2012.

[18] Allacker, K., Environmental and Economic Optimisation of the Floor on Grade in Residential Buildings. The International Journal of Life Cycle Assessment, 17(6), pp. 813-827, 2012.

[19] Allacker, K. \& De Troyer, F., Moving towards a more sustainable Belgian Dwelling stock: the passive standard as the next step? Journal of Green Building, 8(2), pp. 112-132, 2013.

[20] NIS. Socio-economische enquête (translated: socio-economic survey). SEE, Brussels, 2001. 